\title{
The Pedagogic Role of the Arts and Digital Media in the practice of the Ontario Mathematics Curriculum
}

\author{
O Papel Pedagógico das Artes e das Mídias Digitais na Prática do Currículo \\ de Matemática de Ontário
}

Ricardo Scucuglia Rodrigues da Silva*

\begin{abstract}
I have investigated interfaces about the arts and digital media in mathematics education, conceptualizing the notion of digital mathematical performance (DMP). In this article, I discuss connections between: (a) the mathematical strands and processes of the K-8 Ontario Mathematics Curriculum in Canada, and; (b) DMP produced by students. Based on the analysis of twenty-two DMP, I argue that DMP may offer ways to: (1) explore most of the mathematical processes of the Ontario Curriculum, and; (2) open windows into the exploration of math contents. I highlight the educational significance in practicing DMP as an innovative process that integrates multimodality, playfulness, and creativity. In contrast, I have found that the production of DMP does not guarantee the in-depth connection between the math strands and processes of the Curriculum. Generally, students explored contents about Geometry, which is not surprising, regarding the visual nature of both: geometrical and digital media representations.
\end{abstract}

Keywords: Mathematics Education. Digital Videos. Multimodality. Digital Mathematical Performance.

\begin{abstract}
Resumo
Eu tenho investigado interfaces entre as artes e as mídias digitais em educação matemática, conceituando a noção denominada performance matemática digital (PMD). Neste artigo, discuto conexões entre (a) conteúdos e processos que compõem o Currículo de Matemática de Ontário (Canadá) e (b) PMD produzidas por estudantes. Baseados na análise de 22 PMD, argumento que PMD pode oferecer meios para (1) explorar a maioria dos processos matemáticos do Currículo de Ontário e (2) "abrir janelas" para a exploração de conteúdos matemáticos. Destaco a significância educacional da PMD enquanto processo inovador que integra multimodalidade, ludicidade e criatividade. Em contraste, a produção de PMD não garante a conexão profunda entre conteúdos e processos matemáticos do Currículo. De maneira geral, os estudantes exploraram conteúdos de geometria, o que não é surpreendente, pois há uma similaridade entre a natureza visual da representação geométrica e da representação baseada no uso de mídias digitais.
\end{abstract}

Palavras-Chave: Educação Matemática. Vídeos Digitais. Multimodalidade. Performance Matemática Digital.

\section{Digital Mathematical Performance}

Students and teachers have used the arts (e.g., music, drama, cinema, and dance) to represent, communicate, and share their mathematical ideas. Collectively, pupils and

\footnotetext{
${ }^{*} \mathrm{PhD}$ in Education Studies, The University of Western Ontario (UWO), Canada. Professor at the Department of Education, Sao Paulo State University (UNESP), Campus of Sao Jose do Rio Preto, SP, Brazil. Rua Cristóvão Colombo, 2265. Bairro Jardim Nazareth, 15054-000 - São José do Rio Preto, SP. ricardos@ibilce.unesp.br.
} 
educators have produced digital videos of artistic performances created in classrooms and posted them on the Internet in order to share what they have learned about mathematics at school. Parents, relatives and friends of these students, as well researchers, artists, and an embracing audience may easily access these videos on virtual environments and social networks such as YouTube and Facebook. These students' digital artistic performances are also available on universities' websites as the most significant component of research and knowledge mobilization projects (SCUCUGLIA; GADANDIS, 2013; BORBA; SCUCUGLIA; GADANIDIS, 2014).

These projects seek to investigate and disseminate types of pedagogic possibilities for effective innovation in education, highlighting the integrated use of the arts and digital media for mathematical teaching, learning, knowledge production and curriculum practice (see www.mathfest.ca). Thus, one has conceptualized the very notion of digital mathematical performance (DMP) in order to conduct research, teaching and learning activities, and university-schools actions. Authors such as Gadanidis and Borba (2008), for instance, investigated questions like: How can we use the performance arts and digital media to communicate our mathematical ideas? What are roles of the arts and digital media in shaping students' mathematical thinking? Actually, DMP is a potential research trend (being investigated since 2006), and has already achieved acceptance in our community (BORBA; GADANIDIS, 2008; BORBA, 2009; GADANIDIS; GEIGER, 2010; SCUCUGLIA, 2014).

One of the reasons DMP would be meaningful for math education is the fact that it integrates the arts and use of technology in an innovative way, contributing, for instance, to the construction of new images of school mathematical knowledge and practice and new images of mathematicians (GADANIDIS, 2012). Clearly, this study is theoretically located beyond the ordinary comprehensions about what performance means in Education. Usually, performance is taken in educational scenarios in contexts like "students' performance in tests", that is, performance as "success in standardized tests". In the research I am involved with, I explore performance through the lenses of the performance art (GEROFSKY, 2006).

In this regard, one has conceptualized mathematical performance as the process of communicating mathematics through the (performance) art. If students are singing a song to communicate what they learned about triangles in their math class, for instance, I conceive that as an event named math performance. The literature has explored both the process of communication and the digital representations of these communicational processes. It is throughout such semiotic lenses that DMP has been conceptualized as multimodal texts/narratives produced in order to register math performances (SCUCUGLIA, 2012). 
The study reported in this article presents some of the results of a dissertation, which is the first doctoral research about DMP. Scucuglia (2012) analyzed twenty-two DMP produced by Grade 4-6 students from public schools in Ontario, Canada. In this paper, I used the data from de mentioned dissertation, but, focusing on specific aspects to discuss in-depth potential and effective connections between students' production of DMP in schools and the K-8 Ontario Mathematics Curriculum (ONTARIO, 2005).

The developed work was to analyze possibilities in which the pedagogic components and the mathematical strands of the K-8 Ontario Mathematics Curriculum (K-8 OMC) would be explored in classes through the production of DMP. That is, I am actually exploring the question: How does the production of DMP may support mathematical strands and processes of the K-8 OMC? This analysis considers the fact the $\mathrm{K}-8 \mathrm{OMC}$ is comprised by seven mathematical processes and five mathematical strands and which mathematical processes and contents (strands) would be involved in each DMP: the curricular role of DMP as an effective classroom activity regarding the K-8 OMC.

Potentially, this study contributes to the discussion on "research and effective practices in mathematics education". There are several ways to conceptualize what "research and effective practices" mean in mathematics education. It would refer to teaching and learning experiences, research methodologies, philosophical inquiry boundaries, and so on (D'AMBRÓSIO, 2008). In this regard, two important aspects must be pointed out: (1) this study is based on an in-depth research (a doctorate dissertation), and; (2) the data analyzed refer to effective practices conducted in math classes in Canada. Moreover, the paper contributes to the internationalization of UNESP/BOLEMA, which is a significant aspect not only in Brazil, but also in the globalized worldwide academic scenario.

\section{Methodology: introducing the data}

The twenty-two DMP analyzed in this study are publicly available at the Math + Science Performance Festival (see www.edu.uwo.ca/mpc/performances_2008.html). These are all the students' DMP submitted to the Festival in the 2008 season. In this Festival, students, teachers, parents, artists, researchers, and people in general may submit their DMP. The organizers of the Festival make the performance available and every season a collection of judges, comprised of Canadian artists, TV presenters, educators, and worldwidemathematicians indicate their favorite DMP based on three aspects: (a) the conceptual nature of the mathematical idea; (b) creativity, and; (c) artistic and technological components. The 
authors/creators/producers of the indicated DMP in the Festival are awarded with medals from the Fields Institute, the Western University, and the Canadian Mathematical Society (SCUCUGLIA; GADANIDIS, 2013).

In Table 1, I introduce the twenty-two DMP analyzed in the study, indicating a number for each DMP (e.g., \#1, \#2, \#3, and so forth). I also present the title, a screen-captured image, the digital format, and length of the videos. Along the paper, I use the number of each DMP to refer to them (e.g. DMP\#1, DMP\#2, DMP\#3, and so forth).

Table 1 - List of students' DMP analyzed in the study.

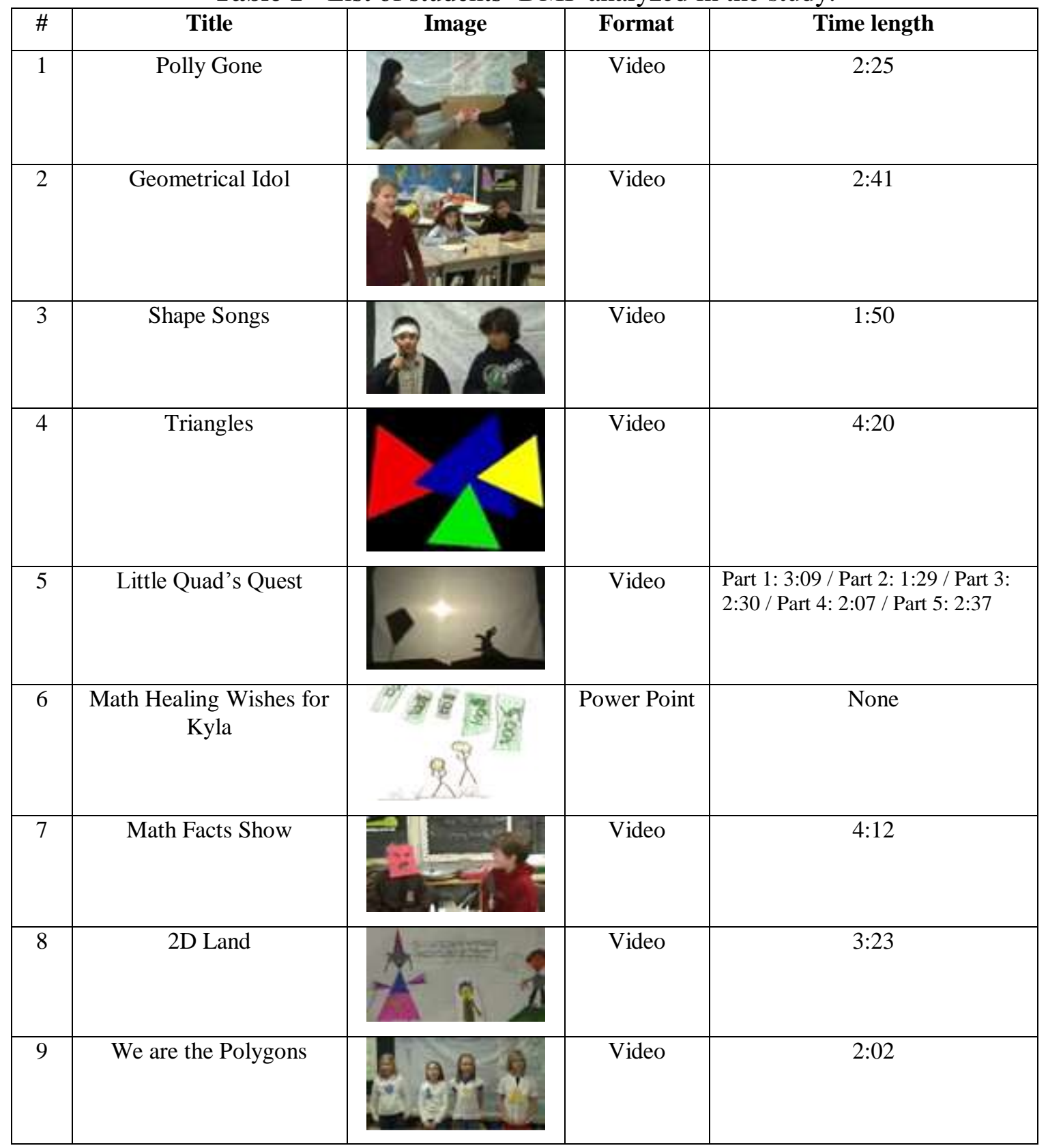




\begin{tabular}{|c|c|c|c|c|}
\hline 10 & Fabulous Fractions & & Video & $0: 38$ \\
\hline 11 & Sphere on the Loose & & Video & $1: 26$ \\
\hline 12 & Radius \& Diameter & & Video & $2: 12$ \\
\hline 13 & Square Trial & & Video & $1: 33$ \\
\hline 14 & Pointacula & & Video & $3: 49$ \\
\hline 15 & Equivalent Fractions & & Video & $0: 37$ \\
\hline 16 & Shape Idol & & Video & $2: 56$ \\
\hline 17 & Square Base pyramid & & Video & $2: 30$ \\
\hline 18 & Who hurt Mr. Square? & & Video & $1: 57$ \\
\hline 19 & $\begin{array}{l}\text { Are You Smarter than a } \\
4^{\text {th }} \text { Grader? }\end{array}$ & & Video & $5: 31$ \\
\hline 20 & $\begin{array}{c}\text { Ricky's Metre Chocolate } \\
\text { Bar }\end{array}$ & & Power Point & None \\
\hline 21 & Grade 5 Math Art & & Image & None \\
\hline 22 & Fractiontastic & & Video & $0: 36$ \\
\hline
\end{tabular}




\subsection{Methodology: theoretical perspectives and procedures}

There are four main methodological aspects in this study. They are:

(M1) In the context of qualitative research, I assumed a role as an interpreter (DENZIN; LINCOLN, 2000). In terms of data collection, I used the notions of judgment sample and theoretical sample proposed by Marshall (2006). I analyzed the twenty-two DMP because these are all the students' DMP in the first year of the Festival (2008) and they offer directionality to support elements to discuss the general research question of the research: What is the nature of elementary school students' DMP at the Math + Science Performance Festival? In the specific case of this paper, the discussed question is: How does the production of DMP may support mathematical strands and processes of the K-8 OMC?

(M2) There are three main bodies of theoretical perspectives forming my interpretative lenses. (M2.1) Boorstin's (1990) categories of "what make good films" to analyze DMP was adapted into mathematics education and, thus, I argue that a conceptual DMP offers mathematical surprises, sense making, emotions, and sensations to the audience. (M2.2.) I analyzed DMP in terms of multimodality (WALSH, 2011), focusing on the modes of communication for mathematics meaning production offered by digital media (e.g., gestures, visual elements, sounds, spatial aspects, vocabularies, use of manipulatives, among others). (M2.3.) I emphasize the role of technology in shaping mathematical knowledge production through representation and communication (BORBA; VILLARREAL, 2005).

(M3) In terms of data analysis, I used the analytic model proposed by Powell, Francisco and Maher (2004), which offers directionality to interpret videos. The model indicates non-linear procedures: viewing and description, coding, identification or selection of critical events, transcription, and composing of the narrative (episodes). In order to analyze each DMP, I developed these procedures in combination with Boorstin's (1990) categories, the notion of multimodality and the components of the K-8 OMC (ONTARIO, 2005).

(M4) Qualitative case studies (STAKE, 2003) are also methodologically significant to this research because (a) my focus is bounded (within the Festival, on Grades 4-6 students' DMP at the 2008 season), and (b) it helps the researcher to delineate ways to tell and represent the stories emerging from the analysis, seeking the depth of understanding of the data, considering the research questions ${ }^{1}$. (M4.1) I conducted single-cases analyses: I

\footnotetext{
1 Stake (2003) claims case studies are specific and bounded, they have patterns, and the focus is on the understanding of the complexity of the case. "Case studies are of value for refining theory and suggesting complexities for further investigation" (STAKE, 2003, p. 156).
} 
analyzed each students' DMP based on Boorstin categories, but also considering issues on multimodality and the components of the K-8 OMC. These analyses had an interpretative/descriptive design. (M4.2) I also conducted cross-cases analyses: I identified similarities and specificities between students' DMP. These analyses had an interpretative/analytic design and offered ways to discuss the components of the K-8 OMC.

In summary, the reader will find in the following sections definitions found in the K-8 $\mathrm{OMC}$ in relation to the analyzed DMP. One will find tables that show similarities about the contents explored on the DMP in relation to the strands of the K-8 OMC.

\section{The K-8 Ontario Mathematics Curriculum}

The K-8 OMC (ONTARIO, 2005) ${ }^{2}$ is comprised by five strands and seven mathematical processes. Notions such as assessment and evaluations are obviously part of the Curriculum as well. The five strands are: (1) Number Sense and Numeration, (2) Measurement, (3) Geometry and Spatial Sense, (4) Patterning and Algebra, and (5) Data Management and Probability. The seven mathematical processes are: (1) problem-solving, (2) reasoning and proving, (3) reflecting, (4) selecting tools and computational strategies, (5) connecting, (6) representing, and (7) communicating. For each grade, the K-8 OMC presents (a) the general context for each strand, (b) expectations for the mathematical processes and (c) specific expectations for each strand in terms of content and processes. There are different levels in which strands and processes overlap in the K-8 OMC (SCUCUGLIA, 2012).

Using Sancristan's (2000) and Heydon's and Wang's (2006) terms, one may state that a prescriptive curriculum is the one in which the design is strict, inflexible. Teachers have to follow the curriculum document, trying to minimize the gap between the official curriculum and the curriculum in action. The focus is on guaranteeing that students are doing what is institutionally/governmentally proposed and thus they will perform well in (standardized) tests, producing fundamental knowledge and developing significant skills in order to achieve professional engagement and success. In contrast, the design of an emergent curriculum is open-ended. The institutional directionality for educational activity promotes diversity for curricula in action. According to Heydon and Wang (2006), in several countries, the nature of the curriculum documents is located in-between the prescriptive and the emergent paradigms: an adaptive curriculum offers balance between efficiency and ethics in terms of students' and

\footnotetext{
${ }^{2}$ Curriculum document available at http://www.edu.gov.on.ca/eng/curriculum/elementary/math18curr.pdf
} 
teachers' roles, content and milieu. Based on these paradigms, the K-8 OMC may be categorized as an adaptable curriculum (SCUCUGLIA, 2012).

The K-8 OMC offers directionality in which teachers, administrators and parents may take decisions and find paths they consider convenient for the students' learning and for their community, among other reasons. For instance, the Ontario Curriculum poses, on the one hand, ways to "mark" students' assessment but, on the other hand, it potentially opens some windows that provide "freedom" to explore different aspects of mathematical activity, including communication, reasoning, use of technology, problem-solving, and so forth.

\subsection{Mathematical strands (contents)}

In most of the DMP (\#1-9, \#11-14, \#16-19, and \#21) students explored ideas about Geometry, in specific, properties and/or examples of plane figures (e.g. polygons and circles) and solids. In DMP \#10, \#15, and \#22 students explored equivalence of fractions, but also made connections to geometric representations. Only in DMP \#6 students explored factorial growth and in DMP \#20 they explored measurement. Among those DMP in which students explored Geometry, in DMP \#1-5, \#7-9, \#12, \#13, \#16, \#18, \#19, and \#21 students explored plane figures (mainly polygons). In DMP \#11, \#14, and \#17 students explored solids, in particular, in DMP \#17, they explored solids and some aspects of the plane figures that form the solids (faces). In Table 2, I present the math contents/ideas explored in each DMP.

Table 2 - Math contents/ideas explored in each DMP.

\begin{tabular}{|c|c|c|c|c|}
\hline \multicolumn{2}{|c|}{ Geometry } & Equivalence of Fractions & $\begin{array}{c}\text { Factorial } \\
\text { Growth }\end{array}$ & Measurement \\
\hline Plane Figures & Solids & $\# 10, \# 15, \# 22$ & $\# 6$ & $\# 20$ \\
$\# 1, \# 2, \# 3, \# 4, \# 5, \# 7, \# 8, \# 9$, & $\# 11, \# 14$, & & & \\
$\# 12, \# 13, \# 16, \# 17, \# 18, \# 19, \# 21$ & $\# 17$ & & & \\
\hline
\end{tabular}

In terms of strands, there is a clear emphasis on Geometry and Spatial Sense regarding the nature of the ideas explored. In the DMP that explore equivalence of fractions, students made connections between two strands - Number Sense and Numeration and Geometry and Spatial Sense - regarding the fact that they used visual/geometric representations of equivalent fractions as parts of representations of rectangles. In DMP \#6, which explores factorial growth, students connected three strands - Number Sense and Numeration, Measurement and Patterning and Algebra - by exploring, for instance, a sequence formed by "twenty dimes" ( $(n=1)$, "twice as much" $(n=2)$, "three times as both of you" $(n=4)$, and so on. In DMP\#20, which explored ways of measuring time and money, students explored ideas 
within the Measurement strand with superficial connections to Number Sense and Numeration. Students did not explore ideas within the Data Management and Probability strand in any of the DMP. In Table 3, I present the strands explored in the DMP.

Table 3 - Strands explored in each DMP.

\begin{tabular}{|c|c|c|c|}
\hline Geometry and Spatial Sense & Number Sense & $\begin{array}{c}\text { Patterning } \\
\text { and Algebra }\end{array}$ & Measurement \\
\hline $\begin{array}{c}\# 1, \# 2, \# 3, \# 4, \# 5, \# 7, \# 8, \# 9, \# 10, \# 11, \# 12, \# 13, \\
\# 14, \# 15, \# 16, \# 17, \# 18, \# 19, \# 21, \# 22\end{array}$ & $\# 6, \# 10, \# 15, \# 20$, & $\# 6$ & $\# 6, \# 20$ \\
\hline
\end{tabular}

Although students explored connections between representations and modes of communication in their DMP, overall, they did not explore many significant connections between strands. According to Gadanidis and Hughes (2008), conceptual DMP explore big mathematical ideas through the articulation between representations and ideas or strands. Therefore, a lack of connections of strands is a characteristic of elementary school students' DMP in the 2008 Festival, because most of the DMP were produced focusing only on the Geometry and Spatial Sense strand. Why did most of the students explore ideas on Geometry in the DMP? One answer would be that Geometry highlights visual representations and the affordances of digital media have a visual nature as well (BORBA; VILLARREAL, 2005).

Students linked the visual nature of Geometry to the visual nature of using videos, making a "comfortable zone" to explore, communicating, and representing ideas. That is, students are exploring visual representations in their DMP, using content only from one area (Geometry) that traditionally explores visualization. The lack of connecting representations and ideas from different strands in students' DMP is also evident in the Curriculum document. By separating and isolating the strands, the Curriculum potentially narrows down the possibilities of articulating multiple representations and strands (SCUCUGLIA, 2012).

Alternatively, the nature of mathematical knowledge in classrooms could be the one of opening windows (NOSS; HOYLES, 1996): DMP has communicational potential to offer ways of opening windows on mathematical meaning production in classrooms. However, the use of DMP does not guarantee the math conceptuality necessarily. The nature of the mathematical idea explored and the use of multiple representations and modes of communication are the most significant aspects in opening windows into mathematics.

\subsection{Problem-solving}

The K-8 OMC states: "problem solving forms the basis of effective mathematics programs and should be the mainstay of mathematical instruction (...) It is considered an 
essential process through which students are able to achieve expectations in mathematics" (ONTARIO, 2005, p. 11). According to the K-8 OMC, problem-solving: - is the primary focus and goal of mathematics in the real world; • helps students
become more confident in their ability to do mathematics; • allows students to use
the knowledge they bring to school and helps them connect mathematics with
situations outside the classroom; - helps students develop mathematical
understanding and gives meaning to skills and concepts in all strands; • allows
students to reason, communicate ideas, make connections, and apply knowledge and
skills; - offers excellent opportunities for assessing students' understanding of
concepts, ability to solve problems, ability to apply concepts and procedures, and
ability to communicate ideas; • promotes the collaborative sharing of ideas and
strategies, and promotes talking about mathematics; • helps students find enjoyment
in mathematics; - increases opportunities for the use of critical-thinking skills
(estimating, evaluating, classifying, assuming, recognizing relationships,
hypothesizing, offering opinions with reasons, and making judgements)
(ONTARIO, 2005, p. 12).

The strategy model mentioned in the Curriculum document is based on (a) understanding the problem; (b) making a plan; (c) carrying out the plan; and (d) looking back at the solution (POLYA, 1957). DMP can be seen in part as a problem-solving experience, because there is a parallel between the strategy model and the process of how to structure mathematics to elucidate the concepts explored considering the presence of surprises, sense making, emotions and sensations, which are the component of "good" narratives within Boorstin's (1990) perspectives. The Curriculum mentions that problem-solving focuses on the "mathematics in the real world (...) helps [student] connect mathematics with situations outside the classroom" (ONTARIO, 2005, p. 12). In DMP\#5 and DMP\#8, for instance, students explored how representations of geometric figures may be identified in the world. In DMP\#12, they used the definitions of radius and diameter of a circle to solve a posed problem of baking a cake regarding specific characteristics of its format. Furthermore, problem-solving highlights "enjoyment in mathematics" and the performative nature of DMP is very playful. DMP offer ways of seeing the joy in mathematics (GADANIDIS; HUGHES; BORBA, 2008).

Skits, songs, musicals, or puppet theatre offers playful, non-traditional and enjoyable environments to explore and communicate mathematics. Collaboration is also an important aspect in problem-solving. It "promotes the collaborative sharing of ideas and strategies, and promotes talking about mathematics" (ONTARIO, 2005, p. 12). All DMP analyzed in this study were produced collectively through collaboration between students (and teachers). All the DMP have two or more authors. Although teachers do not appear as actors or singers in the DMP, the role they played in supporting students in their strategies of performing is fundamental. In the production of DMP, students-teachers-media form thinking collectives in the production of mathematical knowledge (GADANIDIS; BORBA, 2008). 
The use of gestures, verbal language, or manipulatives shapes reorganizes the mathematical thinking emergent from the collective experiences in the classrooms. DMP \#4, for instance, involves a whole class in which many students collaborate with one another by using, for instance, their bodies to create collective representations of triangles in the classroom. Through the notion of collaboration, the students' DMP offer evidence that mathematical experiences in the classroom do not have to be individual and isolated. The joy of mathematics usually emerges from collaborative experiences students have in classrooms and the playfulness of performance arts opens windows into the collectiveness in the pedagogic scenarios, which are significant elements of postmodern curricula (DOLL, 1993).

\subsection{Reasoning and proving}

The reasoning process supports a deeper understanding of mathematics by enabling students to make sense of the mathematics they are learning. The process involves exploring phenomena, developing ideas, making mathematical conjectures, and justifying results ... Students should be encouraged to reason from the evidence they find in their explorations and investigations or from what they already know to be true, and to recognize the characteristics of an acceptable argument in the mathematics classroom. Teachers help students revisit conjectures that they have found to be true in one context to see if they are always true (ONTARIO, 2005, p. 14).

Significant aspects regarding the focus of this study on the nature of students' DMPs refer to students' reasoning, heuristics, understanding, thinking, meaning and knowledge production. In DMP \#1, for instance, students explore the notion of polygons and nonpolygons based on experimental puzzles where they have to think intuitively and deductively to figure out the questions and the solutions of the puzzles. However, I found in this study that there is a lack in terms of sense making in students' DMP. There is some evidence that this lack exist because the DMP are "short" (digital/multimodal) texts/narratives and art in general deals with subjectivity. That is, in music performances such as DMPs \#2 and \#3, for instance, the plot of mathematical ideas is built on a short amount of information and, instead of posing ideas objectively, these DMP use only few words based on rhymes. This characteristic offers insights to the audience, but it does not guarantee that the ideas are being communicated clearly, with sufficient arguments that justify the statements posed. It is not a trivial task to create a conceptual math song. Actually, the production of a conceptual DMP is a rare event (SCUCUGLIA, 2012; SCUCUGLIA; GADANIDIS, 2013). 


\title{
3.4 Reflecting
}

The K-8 OMC states that:

\begin{abstract}
Students' problem solving skills are enhanced when they reflect on alternative ways to perform a task, even if they have successfully completed it. Reflecting on the reasonableness of an answer by considering the original question or problem is another way in which students can improve their ability to make sense of problems. Even very young students should be taught to examine their own thought processes in this way. One of the best opportunities for students to reflect is immediately after they have completed an investigation, when the teacher brings students together to share and analyse their solutions. Students then share strategies defend the procedures they used, justify their answers, and clarify any misunderstandings they may have had. This is the time that students can reflect on what made the problem difficult or easy (e.g., there were too many details to consider; they were not familiar with the mathematical terms used) and think about how they might tackle the problem differently. Reflecting on their own thinking and the thinking of others helps students make important connections and internalize a deeper understanding of the mathematical concepts involved (ONTARIO, 2005, p. 14).
\end{abstract}

The process of producing DMP requires engagement in practicing the performance and may require engagement with use of digital media. The process of practicing a skit, for instance, usually requires practice/repetition to communicate ideas clearly though gestures, actions, speech, and so forth. These processes are fundamental for learning and developing students' communication skills. In the end of DMP \#19, for instance, the audience can listen to the teacher saying the following words to the students when they finish the skit performance: “Ok! Hey guys, that was a lot better!" This comment means that it was not the first time students were presenting the skit. They were practicing the dramatic events, repeating their actions, gestures, and speeches in such way they were seeking to optimize the communication of their mathematical ideas.

Furthermore, typical classroom experiences are not recorded and they are not shared publicly. Each DMP as a product (as a multimodal narrative or multimodal text) offers ways for students and teachers to reflect on their actions and ways of communicating because they can watch or read their DMP as many times they wish after its creation. That is, these experiences help inform or restructure future pedagogic experiences, offering new insights on students' learning based on their previous recorded actions. In this scenario, teachers also may assume a very significant role in helping students to create good stories, that is, teachers play very important pedagogic roles in supporting students on the creation of good multimodal texts in which students use the performance arts to communicate their learning. Within the notion of cognitive ecology (LÉVY, 2000), thinking collectives of students-teachers-DMP may be found in reflective actions even after the creation of the DMP. Conceptual 
mathematical surprises, for instance, may offer ways for students to think mathematically in future events of their lives after the production of a DMP.

DMP are also publicity available online and they may be accessed anytime. Thus, the virtual environment of the Math + Science Performance Festival works as a nexus that offers ways of forming collective intelligences (LÉVY, 2000), with a fundamentally reflective nature. Gadanidis and Geiger (2010, p. 102) have referred to the Festival as "one example that helps bring the mathematical ideas of students into public forums, where it can be shared and critiqued and which then provides opportunity for the continued development of knowledge and understanding within a supportive community of learners”.

Moreover, from a narrative point of view (BRUNER, 1996), the fact that DMP are shared publicly online makes students reflect about their experiences and ways of communicating mathematical ideas to the audience. Thus, the role of the audience shapes the ways students think about their learning and the ways they communicate mathematics in the DMP, because students reflect on how to portray the "mathematical self" to a large audience formed by people that are not necessarily in their classrooms. There is thus the pedagogic dimension in which students construct identities as performance mathematicians by producing a DMP. DMP\#2, \#7, and \#16, for instance, the audience may vicariously feel that students are conscious that they are communicating their mathematical ideas to a wide online audience who is interested in mathematics and these DMP are parodies of popular TV shows.

\subsection{Selecting tools and computational strategies}

Considering the fact that DMP is essentially produced through the use of digital technology, Selecting Tools and Computational Strategies is a very significant process in DMP. The Curriculum document states that:

\footnotetext{
Various types of technology are useful in learning and doing mathematics. Although students must develop basic operational skills, calculators and computers can help them extend their capacity to investigate and analyse mathematical concepts and reduce the time they might otherwise spend on purely mechanical activities. Students can use calculators or computers to perform operations, make graphs, and organize and display data that are lengthier and more complex than those that might be addressed using only pencil-and-paper. Students can also use calculators and computers in various ways to investigate number and graphing patterns, geometric relationships, and different representations; to simulate situations; and to extend problem solving. (... ) Computers and calculators are tools of mathematicians, and students should be given opportunities to select and use the particular applications that may be helpful to them as they search for their own solutions to problems (ONTARIO, 2005, p. 14-15).
} 
The Curriculum also states that "students need to develop the ability to select the appropriate electronic tools, manipulatives, and computational strategies to perform particular mathematical tasks, to investigate mathematical ideas, and to solve problems" (ONTARIO, 2005, p.14). In many DMP students use manipulatives, drawing, and "math costumes" (e.g., DMP \#1, \#4, \#5, \#7-11, \#13-15, \#18, \#21, and \#22) in ways that offer important insights to the audience's mathematical understanding. In DMP\#5, for instance, the use of manipulatives is fundamental for the audience to visualize the different quadrilaterals, identify their properties and make connections between them. The use of these materials shapes the nature of the reflections and mathematical representations that students and audience engage with.

It is important to mention that the use of digital media is a requirement to produce a DMP. Even though in most DMP students do not use information technology in the process of performing (e.g., they do not use computer software), the use of video cameras to produce video files is fundamental to support multimodal communication and of the Internet to make the DMP public texts in a non-traditional format (not print-based). In DMP \#10, \#15, and \#22 (those that explore visual representations of equivalent fractions), the use of manipulatives and computer software for video edition was fundamental to produce the stop-motion animations, which condition the design of the performances and the mathematical meanings students and the audience may produce when they create or read the DMP (SCUCUGLIA, 2012).

\title{
3.6 Connecting
}

Connections, relations, or articulations between procedures and concepts help students develop mathematical understanding.

\begin{abstract}
Experiences that allow students to make connections - to see, for example, how concepts and skills from one strand of mathematics are related to those from another will help them to grasp general mathematical principles. As they continue to make such connections, students begin to see that mathematics is more than a series of isolated skills and concepts and that they can use their learning in one area of mathematics to understand another. Seeing the relationships among procedures and concepts also helps develop mathematical understanding. The more connections students make, the deeper their understanding. In addition, making connections between the mathematics they learn at school and its applications in their everyday lives not only helps students understand mathematics but also allows them to see how useful and relevant it is in the world beyond the classroom (ONTARIO, 2005, p. 16).
\end{abstract}

Connections are one of the most significant aspects analyzed in this research. Connections between representations, for instance, are strongly addressed in the literature on mathematical learning (NOSS; HOYLES, 1996). From the notion of cognitive ecology 
(LÉVY, 2000), communication, learning, and meaning and knowledge production are concerned with connections. In my analysis, I interpreted and explored four overlapping types of connections in students' DMP. These are connections between (a) representations (b) modes of communication; (c) mathematical ideas, concepts, or strands; and (d) mathematical ideas and everyday situations. In DMP\#13, for instance, students perform a skit to explore relations between quadrilaterals, connecting verbal information (speeches), gestures, and visual-manipulative tools (they play roles as quadrilaterals with costumes formed by representations of the figures). The way students make connections between representations and modes of communication offer ways for the audience to make connection between properties of quadrilaterals and relations between them. Although students did not explore connections on everyday situations, these multiple forms of connecting representations, modes, and geometric properties of figures emergent in dramatic events in the DMP offer ways for the audience to explore surprising ideas such as "a square is a special case of rectangle, parallelogram, and rhombus."

Overall, most of the students' DMP connect multiple modes of communication and representations. In fact, it emerges "naturally" because they are using digital media to communicate and represent their ideas. Although some DMP explore connections between mathematics and everyday contexts (e.g, DMP \#2, \#5-9, \#11, \#12, \#16, \#17), most of the connections are superficial or do not present strong arguments to make the connection explicitly to the audience. Only DMP \#6, \#10,\#15, \#20, and \#22 make connections across strands, but these DMP do not fully explore all modes of communication because DMP \#6 and \#20 are in power point format and use only writing and drawing and DMP \#10, \#15, and \#22 are animations in which students do not appear in the performance (no embodied gestures nor verbal information).

\subsection{Representing and communicating}

The K-8 OMC states that:

In elementary school mathematics, students represent mathematical ideas and relationships and model situations using concrete materials, pictures, diagrams, graphs, tables, numbers, words, and symbols. Learning the various forms of representation helps students to understand mathematical concepts and relationships; communicate their thinking, arguments, and understandings; recognize connections among related mathematical concepts; and use mathematics to model and interpret realistic problem situations. Students should be able to go from one representation to another, recognize the connections between representations, and use the different representations appropriately and as needed to solve problems (ONTARIO, 2005, p. 16). 
The modes of representation pointed out in the Curriculum are fundamentally printbased. Typical classrooms experiences students have are not recorded. DMP offers ways for multimodal representations in which students can combine all these modes pointed out in the Curriculum with a vast variety of others including verbal/oral/spoken communication, sound effects and music, gestures, visual simulations, spatial designs, and so forth. Moreover, representing mathematical ideas through the use of the performance arts is not typical as well (GEROFSKY, 2006).

The interdisciplinary aspects that involve mathematics and the arts in DMP offer ways to construct rich pedagogic scenarios. The use of gestures in skits, for instance, opens windows for multiple signs to represent mathematics and adds new layers of meanings. In DMP \#4, for instance, the use of students' bodies to create a collaborative representation of triangles is fundamental for students' and audience's understandings. In DMP \#10, \#15, and \#22 students explore visual proofs for equivalence of fractions through the production of a stop-motion animation. Therefore, DMP offers multiple modes and artistic expressions for students to represent thinking, reasoning, and learning, which challenges the lack in the Curriculum in terms of strictly proposing the print-based format of representing.

The K-8 OMC also posits that:

Communication is the process of expressing mathematical ideas and understanding orally, visually, and in writing, using numbers, symbols, pictures, graphs, diagrams, and words. Students communicate for various purposes and for different audiences, such as the teacher, a peer, a group of students, or the whole class. Communication is an essential process in learning mathematics. Through communication, students are able to reflect upon and clarify their ideas, their understanding of mathematical relationships, and their mathematical arguments... The ability to provide effective explanations, and the understanding and application of correct mathematical notation in the development and presentation of mathematical ideas and solutions, are key aspects of effective communication in mathematics (ONTARIO, 2005, p. 17).

Communication is a key-notion in this study. DMP offers ways for the student to communicate ideas combing several modes: linguistic, visual, gestural, audio, and spatial. The combined use of these designs to communicate mathematics offers surprises to the audience. The multimodal nature of students' DMP is one of its most important pedagogic attributes.

\section{Analytic discussion: practice and multimodal communication}

It is surprising to see students communicating mathematical ideas using performance arts and multiple modes of communication. Digital media offer ways to combine multiple modes of communication such as aural, visual, gestural, spatial, and linguistic (THE NEW LONDON GROUP, 1996). Thus, it is mathematically and pedagogically surprising to 
recognize, see and read the ways elementary school students are representing their learning in each DMP analyzed in this study, by using non-typical elements of the designs of mathematical communication such as gestures and sounds combined with images, visual effects, drawings, verbal and written words, symbols, manipulative materials, spatial elements, and performance arts as well. Multimodality also refers to the synergy between technology and art. Playfulness (including performance arts) and production of multimodal texts are characteristics of sociocultural/postmodern curricula and these aspects are not emphasized in the K-8 OMC. Thus, in Table 4, I present the format of the DMP in relation to the arts performed in the students' DMP.

Table 4 - The format and the performance art in students' DMP.

\begin{tabular}{|c|c|c|c|c|c|c|}
\hline \multicolumn{5}{|c|}{ Video Format } & \multicolumn{2}{|c|}{ Power Point } \\
\hline Musical (Skit + Song) & Skit & Song & Puppet Theatre & Animation & Poem & Drawing \\
\hline $\begin{array}{c}\# 2, \# 4, \# 7, \# 9, \# 14, \\
\# 16, \# 17\end{array}$ & $\begin{array}{l}\# 1, \# 11, \# 12, \\
\# 13, \# 18, \# 19\end{array}$ & $\# 3$ & $\# 5, \# 8$ & $\begin{array}{c}\# 10, \# 15, \\
\# 22\end{array}$ & $\# 6, \# 20$ & $\# 21$ \\
\hline
\end{tabular}

Most of the DMP analyzed in this study were displayed in video format, which requires the use of a video camera and, probably, software of video editing. All the DMP in video format combine all the five designs of modalities. The designs are: linguistic, visual, gestural, spatial, and audio. It is also important to highlight that the process of editing a video is a process of thinking-with-technology (BORBA; SCUCUGLIA; GADANIDIS, 2014). It is a reflective process in which the authors (students and/or teachers) think about what kind of meaning the audience may produce. It is a learning process in which the authors develop sense-making (sense of story) regarding possible signs, representations, and feelings (emotions and sensations) the audience may engage with. It is a process of developing communication skills in clearly representing ideas to an audience (SCUCUGLIA, 2014).

Students used a variety of materials (e.g. costumes, posters, scenarios, modeling clay, papers to represent shapes, and so forth) in their musicals, skits, songs, puppet theatre, and animation performances. These materials are very significant for students' and the audience's meaning production. In DMP \#1, \#4, \#5, \#8, \#10, \#15, and \#22 students used manipulative materials. In DMP \#1, students used paper materials to create representations of polygons and non-polygons, which are part of the puzzle posed. In DMP \#4, students also use paper material to construct representations of triangles to build representations of several figures (e.g. parallelogram and hexagon). In DMP \#5 and \#8 students also used papers and sticks to create the puppet characters that are representations of geometric figures. In DMP \#10, \#15, and \#22 students used paper materials and modeling clay to produce their animations using the stop-motion animation that reveals a visual proof for equivalence of fractions. 
In DMP \#7, \#9, \#11, \#13, \#14, and \#18, the students used costumes that characterize them as geometric objects. These costumes (e.g., masks or figure representations pasted on students' t-shirts) enhance their sense of embodiment and offer visual insights to the audience, which are significant in terms of sense making. These are costumes related to the roles students are playing, which are not necessarily roles as mathematical objects. In DMP \#6, \#8, $\# 11, \# 12, \# 17, \# 19, \# 20$, and \#21, the students used drawings to represent and communicate their mathematical ideas. All the possibilities displayed by producing DMP offer ways to connect the processes of the Curriculum and open windows to explore elements not expected for each process posed in the K-8 OMC (SCUCUGLIA, 2012).

The gestural design of modality is fundamental in DMP. The DMP based on skits are built on the ways students use gestures and motions to communicate mathematics. In DMP $\# 1$, \#2-5, \#7-19, and \#22, gesture can be seen as a mode of communication that shapes the production of mathematical meaning. Gesture is a fundamental resource to think mathematically and communicate ideas with emotions. In fact, the mathematical activity related to the use of the body in mathematics education is explored through the notion of embodiment (GEROFSKY, 2010). Usually, students and teachers use gestures to communicate their ideas in classrooms, but gestures are not typically fixed when students represent their ideas. Traditionally, students represent ideas using print-based texts, which is a format that is not friendly to support the gestural design. Thus, the multimodal design of DMP offers ways for students to communicate and represent their ideas using gestures, which is a significant mode for mathematical meaning production. All the DMP in video format performed through musical, skit and songs used zooming-in (close-ups) on the actors/singers' facial expressions, which is part of the gestural design and may increase the feeling of vicarious emotions for the audience (SCUCUGLIA, 2012).

The audio design of the modality is also fundamental in DMP. The DMP based on skits, songs, musical, and puppet theatre are built on the ways students use speeches or verbal communication to talk about mathematics. In DMP \#1, \#2-5, \#7-9, \#11-14, and \#16-19, orality is a mode that shapes the production of mathematical meaning. Similarly to gestures, students and teachers use verbal words to communicate their ideas in classrooms, but these words are not usually "fixed" when students represent their ideas. Traditionally, students represent ideas using print-based texts, which is a format that does not support the audio design of communication. Thus, the multimodal design of DMP offers ways to communicate their ideas using audio, which is a significant mode for mathematical meaning production. 


\section{Final remarks}

Some of the students' DMP analyzed in this study tend to offer mathematical surprises. These surprises are mostly supported by the use of the performance arts and digital media: multimodality. That is, it is surprising to see students using arts and producing multimodal texts to communicate their mathematical ideas. When students only reproduce typical ideas explored in classrooms (e.g., textbook definitions), for instance, they do not explore the joy and the wonderful side of mathematics. However, some of the students' DMP may potentially offer conceptual mathematical surprises, that is, ways of seeing a new and wonderful aspect in mathematics by connecting multiple representations and multiple strands, connecting mathematics to everyday problems, connecting properties of multiple mathematical objects, or exploring visual proofs. In these senses, the production of DMP goes beyond the K-8 OMC expectations (SCUCUGLIA, 2012).

Most of the ideas explored by students in the DMP are related to Geometry. Students did not investigate several deep connections between strands, considering those proposed in the Ontario Curriculum. Students explored interesting visual representations within Geometry and Spatial Sense, but geometry is traditionally a strand that explores visualization. DMP can be understood as "mirrors" of what and how students are learning in the classrooms and what they are not learning. If they have learned rich visual, concrete representations in Algebra, Number Sense, Measurement, or Probability, they might have explored them in the DMP. Therefore, from a curricular point of view, my analysis is identifying a pedagogical problem.

Components of curricula help the analysis of DMP because they offer elements to identify patterns and gaps on students' ideas, reasoning, ways of reflecting, communicating, representing, connecting, solving problems, and using technology. The production of DMP helps to address the Curriculum mathematical processes in students' classroom activity and, reciprocally, the mathematical processes help in the understanding of the nature of students' DMP. The production of DMP does not guarantee the development of the mathematical processes of the Curriculum, but it offer ways to explore them and to explore processes that are not present in the Curriculum and that are significant for mathematics activity and learning. DMP opens windows into multimodality, creativity and playfulness, which are not fundamental components of the K-8 OMC. However, there are many limitations involving the production of DMP in schools. For instance, the production of DMP requires students' and teachers' knowledge on the integrated use of arts and digital technology. The development of these skills may require engagement and long-time 
pedagogic investment of students and teachers. It may be problematic because the adaptive nature of the K-8 OMC tends to highlight efficacy in several situations, since parents want their children performing well in standardized tests, seeking their access to the university level. Regarding the fact that DMP is a recent theme of research in math education with potential to become a pedagogical trend in the future, I believe this article is contributing with educational significance and some originality to the discussions toward the theme "research and effective practices in mathematics education", that is, to the current special issue of BOLEMA.

The following ongoing stage of this study refers to an analytical investigation toward Brazilian curricula (BRASIL, 1997; SÃO PAULO, 2011) in relation to the K-8 OMC, regarding the role of DMP in math teaching and learning. Superficially, one may recognize direct connections or similarities, such as the methodologies posed, for instance, in the PCN (e.g., problem-solving and use of technology), as well the notion of writing and narrative in mathematics learning presented in the Sao Paulo State Curriculum: DMP as multimodal narratives (SCUCUGLIA, 2014). There are also similarities in terms of contents, although the title and structure of the "blocks" (strands) are different. The in-depth report about this correlational investigation will be properly addressed in a forthcoming paper.

Finally, among other aspects, this paper contributes to the discussion on "research and effective practices in mathematics education" by presenting and analysing exploratory experiences that articulate curriculum mathematical strands and processes to the effective classroom activity or practice based on the production of DMP. The study analyzed several examples or cases in which elementary school students conducted the integrated use of arts and digital technology to practice and learn mathematics. The research investigated how the development of activities on creating DMP may effectively engage students in math processes such as problem-solving, communicating, representing, connecting, reasoning and proving (ONTARIO, 2005).

The research also showed how these processes, in the context of DMP, might offer to students educational resources to construct scenarios to explore contents in Geometry. In fact, as a possibility for future pedagogic practices or experiences of students and teachers in math, and for the development of researches in math education, the study emphasises how relevant the establishment of deep connections between several strands beyond those analyzed/found in the study is, that is, more complex connections between Geometry, Algebra, Number Sense and Numeration, Data Management and Probability, and Measurement. A sample of a math task used in the development of current researches on DMP may be found at 
http://researchideas.ca/wmt/c2c1.html. Through the development of the task, maned "Making 10", students have explored and connected contents on Algebra, Number Sense and Probability (SCUCUGLIA; RODRIGUES, 2015). This is one of the main dimensions to recognize the "research and effective practice" nature of the reported research in this paper.

\section{Acknowledgements}

Research development and report were supported by Coordenação de Aperfeiçoamento de Pessoal de Nivel Superior (CAPES / BEX 0363/10-3) and Conselho Nacional de Desenvolvimento Científico e Tecnológico (CNPq / Universal 484970/2013-5).

\section{References}

BOORSTIN, J. The Hollywood Eye: what makes movies work. New York: Cornelia \& Michael Bessie Books, 1990.

BORBA, M. C. Potential scenarios for Internet use in the mathematics classroom. ZDM Mathematics Education, Berlin, v. 41, n. 4, p. 453-465, Aug., 2009.

BORBA, M. C.; GADANIDIS, G. Virtual communities and networks of practicing mathematics teachers: The role of technology in collaboration. In: WOOD, T.; KRAINER, K. (Ed.). International Handbook of Mathematics Teacher Education. Participants in mathematics teacher education: individuals, teams, communities, and networks (Vol. 3). Rotterdam, Netherlands: Sense, 2008, p. 181209.

BORBA, M. C.; SCUCUGLIA, R.; GADANIDIS, G. Fases das Tecnologias Digitais em Educação Matemática: Sala de Aula e Internet em Movimento. 1ª Ed. Belo Horizonte: Autêntica, 2014.

BRASIL. Ministério da Educação. Secretaria de Educação Fundamental. Parâmetros Curriculares Nacionais: Matemática. Brasília: MEC, 1997.

BRUNER, J. S. The culture of education. Cambridge: Harvard University Press, 1996.

D’AMBRÓSIO, U. Educação Matemática: da teoria à prática. Campinas: Papirus, 2008.

DENZIN, N. K.; LINCOLN, Y. S. (Ed.). Handbook of qualitative research 2.ed. Thousand Oaks: Sage, 2000.

DOLL, W. Curriculum possibilities in a "post-future." Journal of Curriculum and Supervision, Alexandria, v. 8, n. 4, p. 277-292, summer, 1993.

GADANIDIS, G.; BORBA, M. C. Our lives as performance mathematicians. For the Learning of Mathematics, Fredericton, v. 28, n. 1, p. 44-51, Mar., 2008.

GADANIDIS, G.; GEIGER, V. A social perspective on technology enhanced mathematical learning from collaboration to performance. ZDM Mathematics Education, Berlin, v. 42, n.1, p. 91-104, Sept., 2010.

GADANIDIS, G.; HUGHES, J.; BORBA, M. C. Students as performance mathematicians. Mathematics Teaching in the Middle School, Reston, v. 14, n. 3, p. 168-176, Oct., 2008. 
GADANIDIS, G. Why can't I be a mathematician? For the Learning of Mathematics, Fredericton, v. 32, n. 2, p. 20-26, July, 2012.

GEROFSKY, S. Performance space \& time. In: GADANIDIS, G.; HOOGLAND, C. (Ed.). Digital Mathematics Performance - proceedings of a Fields Institute Symposium, London: Western University, 2006.

GEROFSKY, S. Mathematical learning and gesture. Character viewpoint and observer viewpoint in students' gestured graphs of functions. Gesture, Philadelphia, v. 10, n. 2-3, p. 321-343, Mar., 2010.

HEYDON, R.; WANG, P. Curricular ethics in early childhood education programming: A challenge to the Ontario kindergarten program. McGill Journal of Education, Montréal, v. 41, n. 1, p. 29-46, winter, 2006.

LÉVY, P. Cibercultura. Rio de Janeiro: Editora 34, 2000.

MARSHALL, M. N. Sampling for qualitative research. Family Practice, Oxford, v. 13, n. 6, p. 522525, July, 1996.

NOSS R.; HOYLES C. Windows on mathematical meaning: learning culture and computers. Dordrecht: Kluwer Academic, 1996.

ONTARIO. Ministry of Education. Ontario Curriculum: Grades 1 to 8 - Mathematics. Toronto: Queen's Printer, 2005.

POLYA, G. How to solve it. 2. ed. Princeton: Princeton University Press, 1957.

POWELL, A. B.; FRANCISCO, J.; MAHER, C. Uma abordagem à análise de dados de vídeo para investigar o desenvolvimento das ideias matemáticas e do raciocínio de estudantes. Bolema, Rio Claro, v. 17, n.21, p. 81-140, 2004.

SACRISTAN, J. G. O currículo: uma reflexão sobre a prática. 3. ed. Porto Alegre: ArtMed, 2000.

SÃO PAULO. Secretaria da Educação. Currículo do Estado de São Paulo: Matemática e suas tecnologias. 1. ed. São Paulo: SE, 2011.

SCUCUGLIA, R. R. S. On the nature of students' digital mathematical performances: when elementary school students produce mathematical multimodal artistic narratives. Germany: Verlag LAP Lambert Acedemic Publishing, 2012.

SCUCUGLIA, R. Narrativas Multimodais: a imagem dos matemáticos em performances matemáticas digitais. Bolema, Rio Claro, SP, Brasil, v. 28, n.49, p. 950-973, Ago., 2014.

SCUCUGLIA, R.; GADANIDIS, G. Performance matemática: tecnologias digitais e artes na escola pública de ensino fundamental. In: BORBA, M.; CHIARI, A. Tecnologias Digitais e Educação Matemática. São Paulo: Editora Livraria da Física, 2013. p. 325 - 363.

SCUCULGIA, R; RODRIGUES, A. F. B. A. A produção de performances matemáticas digitais nos anos iniciais do ensino fundamental. In: FERNANDES, A. H. A. A (Org.). VI SIMPÓSIO

INTERNACIONAL DE PESQUISA EM EDUCAÇÃ O MATEMÁTICA. 6. 2015, Perinópolis, Anais... Perinópolis, GO; Brasília: SBEM, 2015.

STAKE, R. Case studies. In: DENZIN, N. K.; LINCOLN, Y. S. (Ed.), Strategies of Qualitative Inquiry, $2^{\circ}$. ed. Thousand Oaks: Sage, 2003, p. $134-164$. 
THE NEW LONDON GROUP. A pedagogy of multiliteracies: desening social futures. Harvard Educational Review, Cambridge v. 66, n. 1, p. 60-92, spring, 1996.

WALSH, M. Multimodal Literacy: researching classroom practice. Sydney: Primary Teachers Association of Australia, 2011.

Submetido em Abril de 2015. Aprovado em Agosto de 2015. 